\title{
ANALISIS KEBUTUHAN AREAL PARKIR GEDUNG FAKULTAS TEKNIK UNIVERSITAS LANCANG KUNING
}

\author{
Winayati \\ Program Studi Teknik Sipil UniversitasLancangKuning \\ Jalan Yos Sudarso Km. 8 RumbaiPekanbaru \\ E-mail : winayati@unilak.ac.id \\ Fadrizal Lubis \\ Program Studi Teknik Sipil UniversitasLancangKuning \\ Jalan Yos Sudarso Km. 8 RumbaiPekanbaru \\ E-mail : fadrizal@unilak.ac.id \\ Virgo Trisep Haris \\ Program Studi Teknik Sipil UniversitasLancangKuning \\ Jalan Yos Sudarso Km. 8 RumbaiPekanbaru \\ E-mail : virgo@unilak.ac.id
}

\begin{abstract}
Abstrak
Fakultas Teknik Universitas Lancang Kuning terus mengalami perkembangan baik dari segi sarana dan prasarana maupun jumlah mahasiswanya. Fakultas Teknik lahan parkir sudah tersedia namun belum terfungsikan secara optimal karena masih ada beberapa mahasiswa yang memarkir kendaraannya tidak pada tempatnya dan terkesan belum tertata dengan baik sehingga dari segi keamanan dan kenyamanan tempat parkir juga belum terpenuhi. Luas lahan yang ada dan direncanakan digunakan untuk parkir mobil di sebelah timur dan selatan Kampus Teknik Universitas Lancang Kuning seluas $980 \mathrm{~m}^{2}$. Karakteristik meliputi durasi 3,85, indeks parkir 7,65\%, jumlah kebutuhan parkir 32 kendaraan, dengan demikian, luas lahan parkir yang diperlukan dihitung dengan persamaan $:$ Luas lahan parkir $=$ SRP $\mathrm{x}$ jumlah kendaraan $=2,30 \times 5,0 \times 75=862,5 \mathrm{~m}^{2}$. Dengan luas lahan parkir yang tersedia $980 \mathrm{~m}^{2}$ memenuhi kebutuhan. Selanjutnya, hasil survei kendaraan roda dua yang dilakukan pada hari selasa tanggal 19 Februari 2019 jam 8.00 - 17.00 diperoleh, jumlah kendaraan yang masuk keparkiran motor sebanyak 125 motor, dengan karakteristik durasi rata-rata 3,55 jam, indeks parkir 28\%, kebutuhan parkir 48 SRP, luas lahan yang tersediauntukparkirsepeda motor 7,5 x 60 berada di sebelah barat kampus, Dengan demikian, luas lahan parkir yang diperlukan dihitung dengan persamaan : Luas lahan parkir $=$ SRP $\times$ jumlah kendaraan $=0,75 \times 2,0 \times 125=187,5$

$\mathrm{m}^{2}$, Dengan luasan lahan parkir yang tersedia $450 \mathrm{~m}^{2}$ memenuhi kebutuhan luas lahan yang ada.
\end{abstract}

Kata Kunci : Karakteristik Parkir, Mobil Penumpang, Sepeda Motor 


\begin{abstract}
The Lancang Kuning University Faculty of Engineering continues to develop both in terms of facilities and infrastructure and the number of students. The Faculty of Engineering parking area is available but has not functioned optimally because there are still a number of students who park their vehicles improperly and seem not to be well organized so that in terms of safety and comfort the parking lot has not been fulfilled. The existing and planned land area is used for car parking in the east and south of the Engineering Campus of LancangKuning, covering an area of $980 \mathrm{~m} 2$. The characteristics include the duration of 3.85, parking index $7.65 \%$, the number of parking requirements for 32 vehicles, thus, the required parking area is calculated by the equation: Parking area $=S R P \times$ number of vehicles $=2.30 \times 5.0 \times 75=862.5 \mathrm{~m} 2$. With an available parking area of $980 \mathrm{~m} 2$ meeting the needs. Furthermore, the results of the two-wheeled vehicle survey conducted on Tuesday, February 19, 2019 at 8:00 - 17:00 were obtained, the number of vehicles entering the motorbike parking lot was 125 motorcycles, with characteristics of an average duration of 3.55 hours, parking index 28\%, needs parking 48 SRP, the available land area for motorcycle parking $7.5 \times 60$ is on the west side of the campus. Thus, the required parking area is calculated by the equation: Parking area $=S R P \times$ number of vehicles $=0.75 \times 2$, $0 \times 125=187.5 \mathrm{~m} 2$, With the available parking area $450 \mathrm{~m}^{2}$ meets the existing land area needs.
\end{abstract}

Keywords : Parking Characteristics, Passenger Cars, Motor bikes

\section{A. PENDAhULUAN}

Fakultas Teknik Universitas Lancang Kuning merupakan salah satu pusat kegiatan Pendidikan Tinggi di bidang teknik yang ada di Kota Pekanbaru, tepatnya berada di Jalan Yos Sudarso Km.8 Kecamatan Rumbai. Dalam perkembangan pelayanan pendidikan tinggi, dari tahun ketahun Universitas Lancang Kuning terus mengalami perkembangan baik dari segi sarana dan prasarana maupun jumlah mahasiswanya. Begitu juga dengan Fakultas Teknik Universitas Lancang Kuning terus mengalami perkembangan baik dari segi sarana dan prasarana maupun jumlah mahasiswanya. Permasalahan yang terjadi di kampus Universitas Lancang Kuning saat ini adalah permasalahan angkutan mahasiswa, karena jarak pusat kota dengan lokasi kampus kurang lebih 10 $\mathrm{km}$, dan angkutan missal belum beroperasi sesuai dengan standart operasi angkutan umum, seperti angkutan Bus Transmetro Pekanbaru, rute perjalanan terlalu panjang dan waktu tunggu terlalu lama sehingga mahasiswa lebih memilih angkutan sepeda motor.

Khususnya di Fakultas Teknik lahan parkir sudah tersedia namun belum terfungsikan secara optimal karena masih ada beberapa mahasiswa yang memarkir kendaraannya tidak pada tempatnya dan terkesan belum tertata dengan baik sehingga dari segi keamanan dan kenyamanan tempat parkir juga belum terpenuhi. Untuk menjawab permasalahan tersebut diperlukan analisis kebutuhan areal parkir pada gedung Fakultas Teknik dengan tujuan agar kebutuhan parkir terpenuhi secara optimal serta aman dan nyaman sesuai dengan lingkungan. Metode penelitian pertama dilakukan survei pada lokasil ahan existing tentang ukuran lahan, jenis dan jumlah kendaraan yang diparkir, akses keluar dan masuk, data perkembangan jumlah mahasiswa, dosen dan karyawan dari tahun ketahun, dari data yang didapat dilakukan analisis Kebutuhan parkir, 
yang meliputi karakteristik, kapasitas parkir, yang akan dilakukan penataa nulang areal parkir berdasarkan kebutuhan dilapangan.

\section{B. TINJAUANPUSTAKA}

Terdapat beberapa pengertian parkir serta hal-hal yang berkaitan dengan system perpakiran, antara lain, Menurut Pedoman Teknis Penyelenggaraan Fasilitas Parkir Direktorat Jenderal Perhubungan Darat, (1998) yang menyatakan bahwa parkir adalah suatu keadaan tidak bergerak dari suatu kendaraan yang tidak bersifat sementara. Parkir menurut Budiarto, (2007) adalah tempat pemberhentian kendaraan dalam jangka waktu pendekatan lama, sesuai dengan kebutuhan pengendara. Parkir menurut kamus Bahasa Indonesia dalam jurnal Annam CK, (2011) dapat diartikan sebagai tempat pemberhentian kendaraan beberapa saat. Dari beberapa pendapat di atas mengenai pengertian parkir serta hal-hal yang berkaitan dengan system perpakiran disimpulkan bahwa parkir yaitu keadaan Kendaraan berhenti atau tidak bergerak untuk beberapa saat dan ditinggalkan pengemudinya.

Fasilitas parkir adalah lokasi yang ditentukan sebagai tempat pemberhentian kendaraan yang tidak bersifat sementara untuk melakukan kegiatan pada suatu kurun waktu tertentu. Mengatur perparkiran, bukan hanya kepentingan teknis saja yang harus diperhatikan tapi juga harus diperhatikan masalah keindahan. Adanya kegiatankegiatan atau fasilitas tersebut maka diperlukannya sarana parkir kendaraan yang memadai dan mencukupi karena mengingat keberadaan pusat-pusat kegiatan tersebut akan membangkitkan dan meningkatkan aktivitas kebutuhan parkir.

\section{Karakteristik Parkir}

Data karakteristik parkir akan sangat diperlukan untuk melakukan analisis kondisi operasional dan perancangan pengembangan lahan parkir. Beberapa istilah tentang karakteristik parkir yang harus diketahui agar perencanaan dan pengelolahan parkir dapat dihasilkan dengan baik sesuai fasilitas yang dibutuhkan, diantaranya :

a. Kapasitas Parkir

Kapasitas parkir adalah jumlah kendaraan maksimum yang dapat dilayani oleh suatu lahan parkir selama waktu pelayanan. Besar kecilnya kapasitas suatu lahan parkir akan sangat menentukan besarnya volume kendaraan yang dapat ditampung. Hal ini berarti tingkat kapasitas sangat mempengaruhi dimensi lahan parkir tersebut.

b. Durasi Parkir

Durasi parkir merupakan rentang waktu (lama waktu) kendaraan yang parkir. Lamanya parkir tergantung kepada maksud dan tujuanyang dilakukan.

c. Akumulasi Parkir

Akumulasi parkir adalah jumlah kendaraan yang parkir di suatu tempat pada waktu tertentu. Jika sebelum diadakan pengamatan sudah ada kendaraan yang parkir di lokasi survai maka jumlah kendaraan yang ada tersebut dijumlahkan dalam harga akumulasi yang telah dibuat. Dari hasil yang diperoleh dibuat grafik yang menunjukan persentase kendaraan dalam kurva akumulasi parkir

d. Indeks Parkir

Indeks parkir adalah persentase jumlah kendaraan parkir yang menempati area parkir dengan 
Winayati ., Lubis, F., Haris, V.T. / Analisis Kebutuhan Lahan Parkir/ pp. 39-51

jumlah ruangparkir yang tersedia pada area parkir tersebut. Nilai indeks parkir ini dapat menunjukkan seberapa kapasitas parkir yang terisi.

e. Akumulasi Parkir Rata-rata

Akumulasi parkir rata-rata adalah total dari jumlah kendaraan yang parkir disuatu tempat pada waktu tertentu dibagi dengan jumlah jam parkir.

f. Volume Parkir

Volume parkir adalah jumlah keseluruhan kendaraan yang menggunakan fasilitas yang dihitung dalam kendaraan yang diparkir selama satu hari.

g. Satuan ruang parkir

Satuan ruang parkir adalah ukuran luas efektif untuk meletakkan kendaraan termasuk ruang bebas dan arus lalu lintas dimana dimensi kendaraan dari tahun ketahun cenderung mengecil. Parkir merupakan suatu kebutuhan bagi pemilik kendaraan yang mana pemakai kendaraan menginginkan suatu parkir yang mudah dicapai dan memiliki keamanan yang terjamin.

\section{Pola Parkir di Luar Badan Jalan} Menurut Pedoman Teknis Penyelenggaraan Fasilitas Parkir (Direktorat Jenderal Perhubungan Darat, 1996) pola parkir di luar badan jalan dibagi menjadi : Pola parkir kendaraan dua sisi Pola parkir ini diterapkan apabila ketersediaan ruang cukup memadai.

a. Membentuk sudut $90^{\circ}$

Arah gerak lalu lintas kendaraan dapat satu arah atau dua arah seperti pada gambar 1 .

b. Membentuk sudut $30^{\circ}, 45^{\circ}, 60^{\circ}$ seperti terlihat pada gambar 2 .

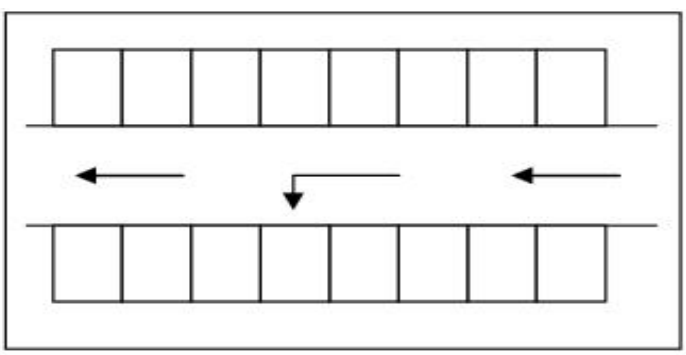

Gambar 1. Pola Parkir Kendaraan Dua Sisi $90^{\circ}$.

(Sumber : Direktorat Jenderal Perhubungan Darat, 1998)

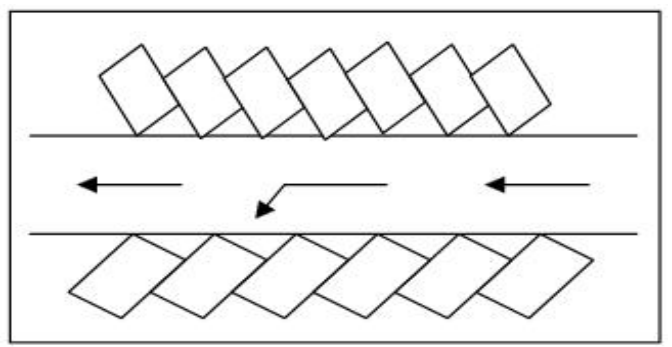

Gambar 2. Pola Parkir Kendaraan Dua Sisi $30^{\circ}, 45^{\circ}, 60^{\circ}$.

(Sumber : Direktorat Jenderal Perhubungan Darat, 1998 


\section{Satuan Ruang Parkir}

Suatu satuan ruang parkir (SRP) adalah ukuran luas efektif untuk meletakan kendaraan. Satuan ruang parkir digunakan untuk mengukur kebutuhan ruang parkir. Tetapi untuk menentukan satuan ruang parkir tidak terlepas dari pertimbanganpertimbangan seperti halnya satuansatuan lain.
Demikian juga halnya untuk menentukan satuan ruang parkir (SRP) didasarkan atas pertimbangan hal sebagai berikut :

a. Satuan ruang parkir untuk mobil penumpang. Gambar 3 merupakan dimensi kendaraan mobil penumpang.
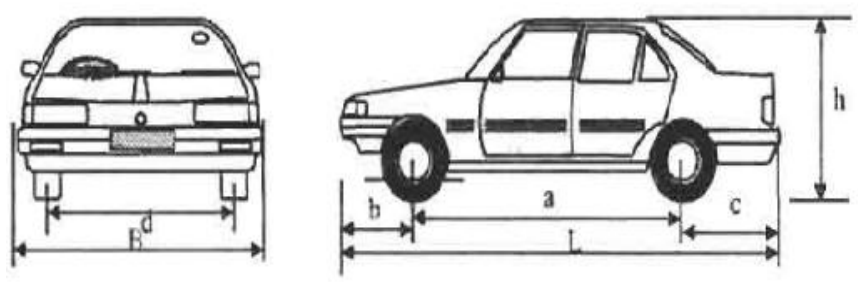

Gambar 3. Dimensi Kendaraan Standar Mobil Penumpang (Sumber : Direktorat Jenderal Perhubungan Darat, 1998)

Keterangan :

$$
\begin{aligned}
& \mathrm{a}=\text { Jarak Gandar } \\
& \mathrm{b}=\text { Depan Tergantung } \\
& \mathrm{c}=\text { Belakang Tergantung } \\
& \mathrm{d}=\text { Lebar Jejak }
\end{aligned}
$$

b. Ruang bebas kendaraan parkir Ruang bebas kendaraan parkir diberikan pada arah lateral dan longitudinal kendaraan. Ruang bebas arah lateral ditetapkan pada saat posisi pintu kendaraan dibuka, yang diukur dari ujung paling luar pintu ke badan kendaraan parkir yang ada di sampingnya. Ruang bebas ini diberikan agar tidak terjadi benturan antara pintu kendaraan dan kendaraan yang parkir di sampingnya pada saat penumpang turun dari kendaraan. Untuk menghindari benturan dengan dinding atau kendaraan yang lewat jalur gang. Jarak bebas arah lateral $\mathrm{h}=$ Tinggi Total

$\mathrm{B}=$ Lebar Total

$\mathrm{L}=$ Panjang Total

diambil sebesar $5 \mathrm{~cm}$ dan jarak bebas arah longitudinal sebesar $30 \mathrm{~cm}$.

c. Lebar bukaan pintu kendaraan

Ukuran lebar bukaan pintu merupakan fungsi karakteristik pemakai kendaraan yang memanfaatkan fasilitas parkir seperti pada Tabel 1.

d. Penentuan satuan ruang parkir (SRP) Berdasarkan tabel penentuan satuan ruang parkir (SRP) dibagi atas tiga jenis kendaraan dan berdasarkan penentuan SRP untuk mobil penumpang diklasifikasikan menjadi tiga golongan, seperti pada Tabel 2. 
Winayati ., Lubis, F., Haris, V.T. / Analisis Kebutuhan Lahan Parkir/ pp. 39-51

Tabel 1. Lebar Bukaan Pintu Kendaraan

\begin{tabular}{|c|c|c|}
\hline $\begin{array}{c}\text { Jenis Bukaan } \\
\text { Pintu }\end{array}$ & $\begin{array}{c}\text { Pengguna dan /atau Peruntukan } \\
\text { Fasilitas Parkir }\end{array}$ & Gol \\
\hline $\begin{array}{l}\text { Pintu depan atau } \\
\text { belakang terbuka } \\
\text { tahap awal } 55 \mathrm{~cm}\end{array}$ & $\begin{array}{l}\text { Karyawan/ pekerja kantor } \\
\text { Tamu/ pengunjung pusat kegitan } \\
\text { perkantoran, } \\
\text { pemerintah, universitas perdagangan, }\end{array}$ & $\mathrm{I}$ \\
\hline $\begin{array}{l}\text { Pintu depan/ belakang } \\
\text { terbuka penuh } 75 \mathrm{~cm}\end{array}$ & $\begin{array}{l}\text { Pengunjungan tempat olahraga, } \\
\text { pusat hiburan/ rekreasi, hotel, pusat } \\
\text { perdagangan, rumah sakit, bioskop }\end{array}$ & II \\
\hline $\begin{array}{l}\text { Pintu depan terbuka } \\
\text { penuh dan ditambah } \\
\text { untuk pergerakan } \\
\text { kursi roda }\end{array}$ & Orang cacat & III \\
\hline
\end{tabular}

(Sumber : Direktorat Jenderal Perhubungan Darat, 1998)

Tabel 2. Penentuan Satuan Parkir (SRP)

\begin{tabular}{clc}
\hline No & \multicolumn{1}{c}{ JenisKendaraan } & SuatuRuanganParkir \\
\hline \multirow{2}{*}{1} & a. Mobil penumpang golongan I & $2,30 \times 5,00$ \\
& b. Mobil penumpang golongan II & $2,50 \times 5,00$ \\
& c. Mobil penumpang golongan III & $3,00 \times 5,00$ \\
& & $3,40 \times 12,50$ \\
3 & Bus/truk & $0,75 \times 2,00$ \\
\hline
\end{tabular}

e. Satuan ruang parkir untuk mobil penumpang

Satuan Ruang Parkir (SRP) untuk mobil penumpang ditunjukkan dalam gambar 4 . f. Satuan ruang parkir untuk sepeda motor

Satuan ruang parkir (SRP) untuk sepeda motor ditunjukkan dalam gambar 5 .

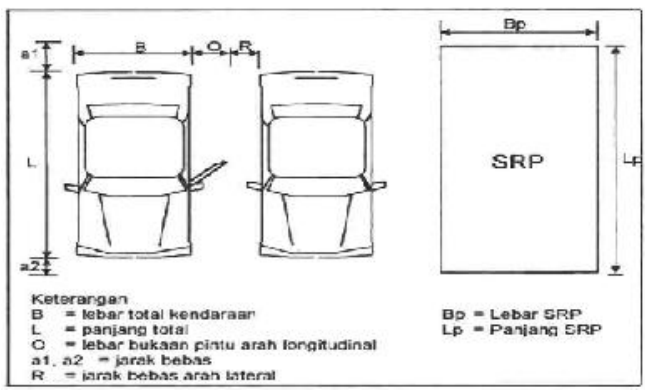

Gambar 4. SRP Untuk Mobil Penumpang (dalam cm)

(Sumber : Direktorat Jenderal Perhubungan Darat, 1998) 


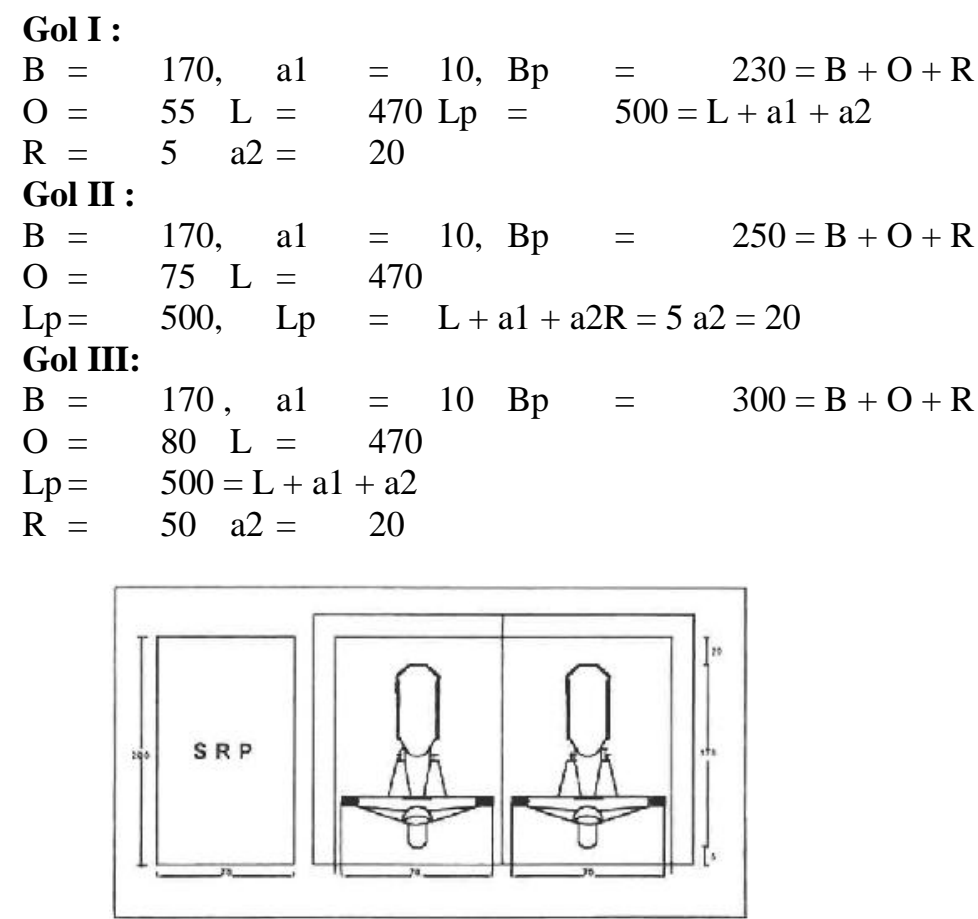

Gambar 5. SRP Untuk Sepeda Motor (dalam cm) (Sumber : Direktorat Jenderal Perhubungan Darat, 1998)

\section{Standar Kebutuhan Ruang Parkir}

Standar kebutuhan luas area parkir berbeda antara yang yang satu dengan yang lain, tergantung kepada beberapa hal antara lain pelayanan, tarif yang diberlakukan. Ketersediaan ruang parkir, tingkat pemilikan kendaraan bermotor, tingkat pendapatan masyarakat. Berdasarkan hasil studi Direktorat Jenderal Perhubungan darat, kegiatan dan standar-standar kebutuhan parkir adalah untuk Sekolah atau Perguruan Tinggi
Parkir sekolah atau perguruan tinggi dikelompokan dalam dua kelompok, yaitu pekerja/ dosen/ guru yang bekerja di sekolah atau perguruan tinggi tersebut dan siswa/ mahasiswa. Pekerja/ dosen/ guru umumnya parkir jangka panjang dan siswa/ mahasiswa umumnya jangka pendek bagi mereka yang diantar jemput dan jangka panjang bagi mereka yang memakai kendaraanya sendiri. Jumlah kebutuhan ruang parkir tergantung kepada jumlah siswa/ mahasiswa.

Tabel 3. Kebutuhan SRP di sekolah atau PerguruanTinggi

\begin{tabular}{ccccccccccc}
\hline $\begin{array}{c}\text { Jumlahsiswa } \\
(100 \text { orang) }\end{array}$ & 30 & 40 & 50 & 60 & 70 & 80 & 90 & 100 & 110 & 120 \\
\hline Kebutuhan SRP & 60 & 80 & 100 & 120 & 140 & 160 & 180 & 200 & 220 & 240 \\
\hline
\end{tabular}

(Sumber : Direktorat Jenderal Perhubungan Darat, 1998) 


\section{METODE PENELITIAN}

Metode pengumpulan data yang digunakan dalam studi ini meliputi :

\section{Studi Literatur}

Membaca literatur yang berhubungan dengan perencanaan lahan parkir, mengumpulkan, mengidentifikasi, permasalahan yang berkaitan dengan permasalahan parkir.

\section{Metode Observasi}

Yaitu metode dengan cara melakukan survey langsung kelapangan. Hal ini mutlak dilakukan untuk mengetahui kondisi sebenarnya. Adapun metode survei yang dilakukan pada studi ini adalah, metode pencatatan nomor kendaraan.

Pengumpulan data diatas adalah sangat penting untuk memperoleh informasi yang dilakukan bagi pelaksanaan penelitian.

a. Data Sekunder

Data sekunder merupakan data pendukung dalam menyelesaikan perencanaan ini, yang meliputi : Standar-standar dan asumsi perparkiran

\section{b. Data Primer}

Merupakan data yang didapatkan dengan cara turun langsung ke lapangan seperti :

1). Geometrik lahan parkir

2). Pintu masuk dan keluar

3). Jumlah kendaraan masuk dan keluar

4). Foto-foto kondisi parkir yang ada

Analisis data adalah proses perhitungandari data primer atau data sekunder, biasanya terdiri dari sejumlah tahapan yang dilakukan secara berurutan. Adapun analisis data yang dilakukan adalah menghitung karakteristik parkir dengan menggunakan rumus:

1. Akumulasi kendaraan yang parkir $\begin{aligned} & \text { Akumulasi } \\ & \text { parkir }\end{aligned} \mathrm{E}_{\mathrm{i}}-\mathrm{E}_{\mathrm{x}}$

Keterangan :

$\mathrm{E}_{\mathrm{i}}=$ Entry (kendaraan yang masuk kelokasi parkir)

$\mathrm{E}_{\mathrm{x}}=$ Extry (kendaraan yang keluar lokasi parkir)

Jika sebelum diadakan pengamatan sudah ada kendaraan yang parkir di lokasi survei maka jumlah kendaraan yang ada tersebut dijumlahkan dalam harga akumulasi yang telah dibuat, dengan rumus :

$$
\begin{aligned}
& \text { Akumulasi } \\
& \text { parkir }
\end{aligned}=E_{i}-E_{x}+X
$$

Keterangan :

$\mathrm{X}=$ Jumlah kendaraan yang ada

Dari hasil yang diperolehdibuat grafik yang menunjukan persentase kendaraan dalam kurva akumulasi karakteristik.

2. Durasi parkir

Durasi parkir $=E_{x}$ waktu $-E_{n}$ waktu (3)

Keterangan :

$$
\begin{aligned}
E_{\mathrm{x}} \text { waktu } & =\begin{array}{l}
\text { Saat kendaraan keluar } \\
\text { dari lokasi parkir }
\end{array} \\
\mathrm{E}_{\mathrm{n}} \text { waktu } & =\begin{array}{l}
\text { Saat kendaraan masuk } \\
\text { dari lokasi parkir }
\end{array}
\end{aligned}
$$

3. Indeks parkir

Indeks parkir

$=\frac{\text { AkumulasiParkir } \times 100 \%}{\text { RuangParkirTersedia }}$

4. Turn over parking

Turn over parking

$$
=\frac{\text { VolumeParkir }}{\text { RuangParkirTersedia }}
$$


5. Volume Parkir

Volume parkir $=\mathrm{E}_{\mathrm{i}}+\mathrm{X}$

Keterangan :

$$
\begin{aligned}
\mathrm{E}_{\mathrm{i}}= & \text { Entry (kendaraan yang masuk } \\
& \text { lokasi) } \\
\mathrm{X}= & \text { Kendaraan yang sudah ada }
\end{aligned}
$$

\section{HASIL DAN PEMBAHASAN \\ 1. Analisis Kebutuhan Parkir}

Analisis kebutuhan ruang parkir yang dilakukan, diperuntukkan bagi dua jenis kendaraan yang akan diparkir yaitu kendaraan roda dua (sepeda motor) dan kendaraan roda empat (mobil penumpang), analisis meliputi jenis kendaraan karakteristik parkir serta satuan ruang parkir. Analisis karakteristik parkir kendaraan dilakukan guna mendapatkan nilai durasi parkir, indeks parkir dan kebutuhan ruang parkir. Dalam analisis ini digunakan data luasan areal yang tersedia untuk parkir kendaraan dan jumlah kendaraan yang keluar masuk areal perparkiran serta satuan ruang parkir (SRP) yang akan digunakan untuk menghitung kebutuhan lahan parkir setiap jenis kendaraan yang akan diparkir di areal kampus Fakultas Teknik Universitas Lancang Kuning.

\section{Luasan Lahan Parkir}

Luasan lahan yang dipergunakan untuk areal parkir saat ini sangat memungkinkan untuk dilakukan penataan karena lahan relative masih kosong, dengan adanya rencana pengembangan kampus, maka akan mempersempit lahan untuk parkir sehingga perlu dilakukan penataan/ pengaturan berdasarkan kebutuhan, seperti yang dapat dilihat pada gambar 4 .

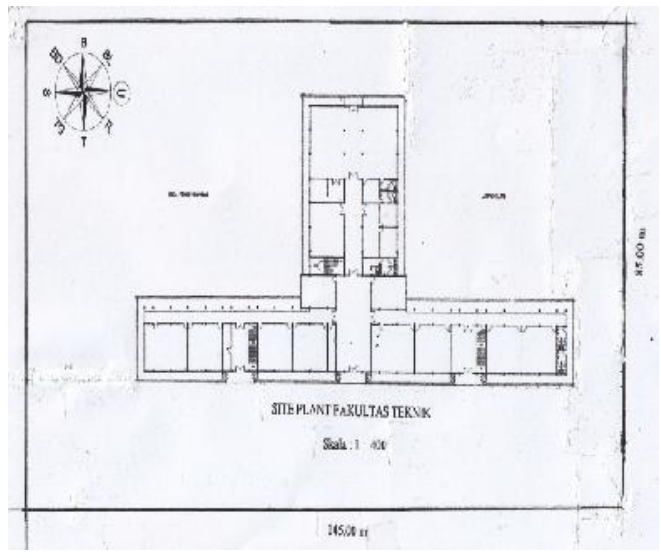

Gambar 4. Site Plant Kampus Fakultas Teknik

Tabel 4. Data Warga Kampus Fakutas Teknis Tahun 2018

\begin{tabular}{clc}
\hline No & \multicolumn{1}{c}{ Uraian } & Jumlah (Orang) \\
\hline 1 & Mahasiswa & 755 \\
2 & Dosen & 36 \\
3 & Karyawan & 5 \\
Total & & $\mathbf{7 9 6}$ \\
\hline
\end{tabular}

Tabel 5. Luasan Lahan yang Tersedia untuk Parkir

\begin{tabular}{clrl}
\hline No & \multicolumn{1}{c}{ Uraian } & $\begin{array}{r}\text { Luas } \\
\left(\boldsymbol{m}^{\mathbf{2}}\right)\end{array}$ & \multicolumn{1}{c}{$\begin{array}{c}\text { Rencana } \\
\text { Peruntukan }\end{array}$} \\
\hline 1 & Depan Kampus (Arah Timur) & $\pm 700 \mathrm{~m}^{2}$ & Parkir roda 4 dosen \\
2 & Samping Kampus( Arah Utara $)$ & $\pm 280 \mathrm{~m}^{2}$ & $\begin{array}{l}\text { Parkir roda 4 dosen dan } \\
\text { mahasiswa }\end{array}$ \\
& & & Parkir roda 2 mhs \\
3 & Belakang Kampus & $\pm 450 \mathrm{~m}^{2}$ & \\
& Total & $\mathbf{1 4 3 0 \mathbf { m } ^ { 2 }}$ & \\
\hline
\end{tabular}

(Sumber : Hasil Survey, 2018) 
Winayati ., Lubis, F., Haris, V.T. / Analisis Kebutuhan Lahan Parkir/ pp. 39-51

Tabel 6. Perhitungan Volume dan Akumulasi Parkir Sepeda Motor

\begin{tabular}{|c|c|c|c|c|c|}
\hline No & Waktu & Masuk & Keluar & $\begin{array}{l}\text { Akumulasi } \\
\text { Parkir }\end{array}$ & $\begin{array}{l}\text { Volume } \\
\text { Parkir }\end{array}$ \\
\hline 1 & $8.00-8.15$ & 10 & 0 & 10 & 8 \\
\hline 2 & $8.15-8.30$ & 15 & 0 & 25 & 25 \\
\hline 3 & $8.30-8.45$ & 8 & 0 & 33 & 33 \\
\hline 4 & $8.45-9.00$ & 5 & 0 & 38 & 38 \\
\hline 5 & $9.00-9.15$ & 3 & 3 & 38 & 41 \\
\hline 6 & $9.15-9.30$ & 3 & 2 & 39 & 44 \\
\hline 7 & $9.30-9.45$ & 4 & 2 & 41 & 48 \\
\hline 8 & $9.45-10.00$ & 5 & 5 & 41 & 53 \\
\hline 9 & $10.00-10.15$ & 1 & 4 & 38 & 54 \\
\hline 10 & $10.15-10.30$ & 2 & 2 & 38 & 56 \\
\hline 11 & $10.30-10.45$ & 3 & 4 & 37 & 59 \\
\hline 12 & $10.45-11.00$ & 2 & 3 & 36 & 61 \\
\hline 13 & $11.00-11.15$ & 2 & 3 & 35 & 63 \\
\hline 14 & $11.15-11.30$ & 3 & 6 & 32 & 66 \\
\hline 15 & $11.30-11.45$ & 2 & 4 & 30 & 68 \\
\hline 16 & $11.45-12.00$ & 0 & 3 & 27 & 68 \\
\hline 17 & $12.00-12.15$ & 2 & 2 & 27 & 70 \\
\hline 18 & $12.15-12.30$ & 5 & 10 & 22 & 75 \\
\hline 19 & $12.30-12.45$ & 4 & 4 & 22 & 79 \\
\hline 20 & $12.45-13.00$ & 4 & 4 & 22 & 83 \\
\hline 21 & $13.00-13.15$ & 4 & 4 & 22 & 867 \\
\hline 22 & $13.15-13.30$ & 4 & 4 & 22 & 91 \\
\hline 23 & $13.30-13.45$ & 5 & 6 & 21 & 96 \\
\hline 24 & $13.45-14.00$ & 0 & 5 & 16 & 100 \\
\hline 25 & $14.00-14.15$ & 4 & 6 & 14 & 102 \\
\hline 26 & $14.15-14.30$ & 2 & 3 & 13 & 102 \\
\hline 27 & $14.30-14.45$ & 0 & 4 & 9 & 104 \\
\hline 28 & $14.45-15.00$ & 2 & 3 & 8 & 105 \\
\hline 29 & $15.00-15.15$ & 1 & 4 & 5 & 107 \\
\hline 30 & $15.15-15.30$ & 3 & 7 & 1 & 108 \\
\hline 31 & $15.30-15.45$ & 3 & 2 & 2 & 111 \\
\hline 32 & $15.45-16.00$ & 0 & 2 & 0 & 111 \\
\hline 33 & $16.00-16.15$ & 4 & 3 & 1 & 115 \\
\hline 34 & $16.15-16.30$ & 4 & 2 & 3 & 119 \\
\hline 35 & $16.30-16.45$ & 3 & 5 & 1 & 122 \\
\hline \multirow[t]{2}{*}{36} & $16.45-17.00$ & 3 & 4 & 0 & 125 \\
\hline & & 125 & 125 & & \\
\hline
\end{tabular}

a. Analisis Kebutuhan Ruang Parkir Sepeda Motor

Dari data keluar masuk kendaraan roda dua serta analisis yang telah dilakukan pada tabel 6 dapat dihitung beberapa karakteristik parkir antara lain durasi, indeks, dan kebutuan parkir sebagai berikut :
1). Durasi Parkir, dari data kendraan roda 2 yang masuk pada area parkir dan telah di cocokkan dengan waktu keluarnya, maka durasi total adalah 26617,50/125 $=212,92$ menit. Dengan jumlah kendaraan masuk 125 kendaraan, maka rata rata durasi parkir per sepeda motor adalah 3,55 jam. 
2). Indeks Parkir $=$ akumulasiparkir $\mathrm{x} 100 \%$ dibagi ruang parkir yang tersedia $=125 \times 100 / 450=$ 27,77

3). Kebutuhan Parkir $=$ jml kend. Parkir x durasi rata-rata parkir / lama waktu pengamatan $=125 \mathrm{x}$ $3.55 / 9=49.3$ kend.

Dengan memperhitungkan Satuan Ruang Parkir (SRP) kendaraan roda dua $=0,75 \times 2,00=1,5 \mathrm{~m}^{2}$, Jumlah kendaraan hasil survey $=125$ kendaraan, dan luas lahan yang tersedia $7,5 \times 60=450 \mathrm{~m}^{2}$ yang berada di sisi Utara kampus, Sehingga dibutuhkan $125 \times(0,75 \mathrm{x}$ $2,00)=187,5 \mathrm{~m}^{2}$ lebih kecil dari luasan lahan yang tersedia (memenuhi).

Tabel 7. Persentasi Komulatif dan Durasi Parkir Mobil

\begin{tabular}{|c|c|c|c|c|c|}
\hline No & Waktu & Masuk & Keluar & $\begin{array}{c}\text { Akumulasi } \\
\text { Parkir }\end{array}$ & $\begin{array}{l}\text { Volume } \\
\text { Parkir }\end{array}$ \\
\hline 1 & $8.00-8.15$ & 5 & 0 & 5 & 5 \\
\hline 2 & $8.15-8.30$ & 6 & 0 & 11 & 11 \\
\hline 3 & $8.30-8.45$ & 4 & 0 & 15 & 15 \\
\hline 4 & $8.45-9.00$ & 2 & 0 & 17 & 17 \\
\hline 5 & $9.00-9.15$ & 2 & 1 & 18 & 19 \\
\hline 6 & $9.15-9.30$ & 1 & 0 & 19 & 20 \\
\hline 7 & $9.30-9.45$ & 2 & 2 & 19 & 22 \\
\hline 8 & $9.45-10.00$ & 3 & 2 & 20 & 25 \\
\hline 9 & $10.00-10.15$ & 4 & 1 & 23 & 29 \\
\hline 10 & $10.15-10.30$ & 1 & 2 & 22 & 30 \\
\hline 11 & $10.30-10.45$ & 2 & 2 & 22 & 32 \\
\hline 12 & $10.45-11.00$ & 1 & 1 & 22 & 33 \\
\hline 13 & $11.00-11.15$ & 0 & 3 & 19 & 33 \\
\hline 14 & $11.15-11.30$ & 2 & 4 & 17 & 35 \\
\hline 15 & $11.30-11.45$ & 1 & 4 & 14 & 36 \\
\hline 16 & $11.45-12.00$ & 0 & 3 & 11 & 36 \\
\hline 17 & $12.00-12.15$ & 1 & 2 & 10 & 37 \\
\hline 18 & $12.15-12.30$ & 3 & 2 & 11 & 40 \\
\hline 19 & $12.30-12.45$ & 2 & 2 & 11 & 42 \\
\hline 20 & $12.45-13.00$ & 3 & 2 & 12 & 45 \\
\hline 21 & $13.00-13.15$ & 4 & 2 & 14 & 49 \\
\hline 22 & $13.15-13.30$ & 5 & 2 & 17 & 54 \\
\hline 23 & $13.30-13.45$ & 3 & 2 & 18 & 57 \\
\hline 24 & $13.45-14.00$ & 1 & 3 & 15 & 58 \\
\hline 25 & $14.00-14.15$ & 2 & 3 & 14 & 60 \\
\hline 26 & $14.15-14.30$ & 3 & 2 & 15 & 63 \\
\hline 27 & $14.30-14.45$ & 0 & 2 & 13 & 63 \\
\hline 28 & $14.45-15.00$ & 2 & 2 & 12 & 65 \\
\hline 29 & $15.00-15.15$ & 2 & 2 & 12 & 67 \\
\hline 30 & $15.15-15.30$ & 1 & 3 & 10 & 68 \\
\hline 31 & $15.30-15.45$ & 1 & 2 & 9 & 69 \\
\hline 32 & $15.45-16.00$ & 0 & 2 & 8 & 69 \\
\hline 33 & $16.00-16.15$ & 2 & 3 & 7 & 71 \\
\hline 34 & $16.15-16.30$ & 2 & 2 & 7 & 73 \\
\hline 35 & $16.30-16.45$ & 2 & 6 & 3 & 75 \\
\hline \multirow[t]{2}{*}{36} & $16.45-17.00$ & 0 & 4 & 0 & 75 \\
\hline & & 75 & 75 & & \\
\hline
\end{tabular}


b. Analisis Kebutuhan Ruang Parkir Mobil

Data kendaraan roda empat yang dianalisis adalah data yang diambil pada hari sabtu bulan Februari tahun 2019, dimana pada hari sabtu jumlah kendaraan yang parkir di areal parkir fakultas Teknik mempunyai volume yang maksimun. Dari data keluar masuk kendaraan roda empat (tabel 7) serta analisis yang telah dilakukan pada tabel di atas dapat dihitung beberapa karakteristik parkir antara lain durasi, indeks, dan kebutuan parkir sebagai berikut :

1). Durasi Parkir, dari data kendraan roda 4 yang masuk pada area parkir dan telah di cocokkan dengan waktu keluarnya, maka durasi total adalah 17332,50/75 = 231,1 menit. Dengan jumlah kendaraan masuk 75 kendaraan, maka rata-rata durasi parkir per sepeda motor adalah 3,85 jam.

2). Indeks Parkir= akumulasi parkir $\mathrm{x} 100 \%$ dibagi ruang parkir yang tersedia $=75 \times 100 / 980=7,65$

3). Kebutuhan Parkir $=$ jumlah kend. Parkir x durasi rata-rata parkir / lama waktu pengamatan $=75 \mathrm{x}$ $3.85 / 9=32.08$ kend.

Dengan memperhitungkan Satuan Ruang Parkir (SRP) kendaraan roda empat $=2.30 \times 5,00=11,5 \mathrm{~m}^{2}$, Jumlah kendaraan hasil survey $=75$ kendaraan, dan luas lahan yang tersedia $980 \mathrm{~m}^{2}$ yang berada di sisi timur dan utara kampus, Sehingga dibutuhkan luasan lahan untuk parkir mobil $75 \times(11,5)=862,5 \mathrm{~m}^{2}$ lebih kecil dari $980 \mathrm{~m}^{2}$ (memenuhi).

\section{Pembahasan}

Dalam Pedoman dan Pengoperasian Fasilitas Parkir yang dikeluarkan oleh Dirjen Perhubungan Darat, Satuan Ruang Parkir untuk mobil penumpang golongan satu adalah 2,30 x $5,0 \mathrm{~m}^{2}=11,5 \mathrm{~m}^{2}$. Selanjutnya, luas lahan yang ada dan direncanakan digunakan untuk parkir mobil di sebelah Timur dan selatan Kampus Teknik Universitas Lancang Kuning seluas $980 \mathrm{~m}^{2}$. Hasil survey kendaraan yang dilakukan pada hari Sabtu tanggal 16 Februari 2019 jam 8.00 - 18.00 menunjukkan jumlah kendaraan yang masuk keparkiran mobil sebanyak 75 mobil. Dengan karakteristik meliputi durasi 3,85, indeks parkir $7,65 \%$, jumlah kebutuhan parkir 32 kendaraan, dengan demikian, luas lahan parkir yang diperlukan dihitung dengan persamaan : Luas lahan parkir $=\mathrm{b}$ SRP $\mathrm{x}$ jumlah kendaraan $=2,30 \times 5,0 \times 75=$ $862,5 \mathrm{~m}^{2}$. Dengan luas lahan parkir yang tersedia $980 \mathrm{~m}^{2}$ memenuhi kebutuhan. Selanjutnya, hasil survei kendaraan roda dua yang dilakukan pada hari selasa tanggal 19 Februari 2019 jam 8.00 17.00 diperoleh, jumlah kendaraan yang masuk keparkiran motor sebanyak 125 motor, dengan karakteristik durasi ratarata 3,55 jam, indeks parkir 28\%, kebutuhan parkir 48 SRP, luas lahan yang tersedia untuk parkir sepeda motor 7,5 x 60 berada di sebelah Barat kampus, Dengan demikian, luas lahan parkir yang diperlukan dihitung dengan persamaan : Luas lahan parkir $=\mathrm{SRP} \times$ jumlah kendaraan $=0,75 \times 2,0 \times 125=187,5 \mathrm{~m} 2$, Dengan luasan lahan parkir yang tersedia $450 \mathrm{~m}^{2}$ memenuhi kebutuhan luas lahan yang ada.

\section{E. KESIMPULAN}

Berdasarkan hasil penelitian yang dilakukan bisa diambil beberapa kesimpulan

1. Luas lahan direncanakan digunakan untuk parkir mobil di sebelah Timur dan selatan Kampus Teknik Universitas Lancang Kuning seluas $980 \mathrm{~m}^{2}$ memenuhi kebutuhan. 
2. Luas lahan yang tersedia untuk parkir sepeda motor sebelah Barat kampus, dengan luasan lahan parkir yang tersedia $450 \mathrm{~m}^{2}$ memenuhi kebutuhan luas lahan yang ada.

\section{DAFTAR PUSTAKA}

Direktorat Jenderal Perhubungan Darat. 1998. Pedoman Perencana Pengoperasian Fasilitas Parkir, Jakarta.

Peraturan Pemerintah. No. 43 Tahun 1993. Tentang Pengaturan Parkiran.

Ali W. 2015. Evaluasi Kapasitas Kebutuhan Gedung Parkir Sepeda Motor dan Mobil Study Kasus di Mall Grand Metropolitan Bekasi.
Jakarta: Program Sarjana

Universitas Mercu Buana Jakarta.

Annam CK. 2011. Analisis Kapasitas

Ruang Parkir Sepeda Motor Off

Street Rumah Sakit Telogorejo

Semarang (Skripsi). Semarang:

Program sarjana. Universitas Negeri

Semarang.

Arif B dan Amirotul. 2007. Rekayasa

Lalu Lintas, Lembaga Pengembangan Pendidikan,

Surakarta

Iskandar A. dkk. 1998. Pedoman Perencanaan dan Pengoperasian Fasilitas Parkir, Direktorat Bina Sistem Lalu Lintas Angkutan Kota dan Direktorat Jenderal Perhubungan Darat, Jakarta. 